\title{
"Meninos não Choram": GÊNERo E Saúde entre Meninos de Classes Populares Urbanas
}

\author{
Elias Barreiros ${ }^{1}$
}

\begin{abstract}
Resumo
Neste artigo discute-se o imaginário e as práticas sociais de jovens, especialmente meninos, de classes populares urbanas acerca da sexualidade e do gênero. Apresenta-se as dificuldades e possibilidades de trabalhos de prevenção entre os mesmos e as implicações da (re)produção de valores hegemônicos referentes à masculinidade, como por exemplo, a heterossexualidade e a virilidade. Um importante viés para entendermos a construção social das masculinidades, são as questões relacionadas à saúde reprodutiva e à sexualidade. Assim, investigar a construção das masculinidades torna-se um importante instrumento para possibilitar uma maior equidade entre os gêneros, bem como para com a prevenção das DSTs, HIV e aids.

Palavras chave: Juventude. Gênero. Masculinidades. Sexualidade.

Abstract

This article discusses the imaginary and the social practices of young people, specially boys, from urban popular classes about sexuality and gender. It presents the difficulties and possibilities of preventive work among them and the implications of the (re)production of hegemonic values concerning masculinity, as for instance heterosexuality and manliness. The questions related to reproductive health and sexuality are an important bias to understand the social construction of masculinities. To investigate the construction of masculinities becomes an important instrument in order to open up the possibility of more gender equity, and also for the prevention of STDs, HIV and AIDS.
\end{abstract}

Keywords: Youth. Gender. Masculinities. Sexuality.

\footnotetext{
${ }^{1}$ Mestrando em Antropologia Social, Universidade Federal de Santa Catarina (UFSC).

e-mail: elias_barreiros@yahoo.com.br
} 


\section{INTRODUÇÃO}

artigo aqui apresentado faz parte de minha pesquisa realizada para conclusão do curso de bacharelado em Ciências Sociais, na Universidade Estadual de Londrina, no ano de 2004. 0 título já aponta os principais temas abordados no trabalho, no qual busco traçar as inter-relações do gênero, enfatizando as questões em torno da construção da(s) masculinidade(s), as relações entre sexualidade e classe social, bem como as dificuldades de prevenção em relação às DST/Aids, foco principal da investigação.

Os dados foram coletados a partir da minha participação em três projetos de prevenção às DST/Aids que tiveram oficinas com dinâmicas e discussões em grupo como metodologia: 1) o projeto de extensão universitária, desenvolvido entre 1999 e 2002 junto a um serviço público de saúde de atendimento a adolescentes; 2) o projeto de prevenção desenvolvido junto a uma Organização Não-Governamental - ONG de Londrina, do qual participei como voluntário e facilitador de oficinas de prevenção para jovens, realizadas em três bairros da cidade, entre 2001 e 2002; 3) e as oficinas de prevenção e discussões em grupo, por mim realizadas, como voluntário, durante o ano de 2003, em uma instituição municipal técnico profissionalizante que trabalhava até aquele momento com cerca de 270 rapazes, de 12 a 18 anos de idade, residentes de várias regiões de Londrina.

Nas oficinas que participei em ambos os projetos a maioria dos jovens tinha entre 14 e 16 anos de idade. Em média as oficinas eram realizadas com 15 jovens. No projeto 1 eram realizadas quatro oficinas seqüenciadas com um mesmo grupo e com os seguintes temas:

a) 0 corpo que sente prazer: sexualidade;

b) 0 corpo que se reproduz: métodos contraceptivos;

c) 0 corpo que adoece: DSTs;

d) Oficina de sexo mais seguro: Aids.

0 projeto 2 também seguiu essa sequiência de quatro oficinas por grupo. No projeto 3 não houve a mesma seqüência, sendo realizado cerca de 30 oficinas com um grupo de jovens meninos 2 . No total cerca de 100 jovens participaram da pesquisa.

A participação nas oficinas e nos grupos de discussão me possibilitou cotejar as opiniões expressas pelos jovens com a bibliografia sobre sexualidade, gênero e saúde, oriunda das Ciências Sociais e da área da Saúde. Pude perceber, desde o início, como

\footnotetext{
${ }^{2}$ A partir de agora quando for me referir a cada um dos projetos, vou me utilizar de projeto $1,2 \mathrm{e} 3$, de acordo com a ordem que os projetos foram apresentados.
} 
determinados valores, referentes à masculinidade, permeiam 0 imaginário dos jovens garotos das classes populares.

Para análise deste conteúdo vou centrar-me no material recolhido através do diário de campo, de um questionário com questões abertas e de recursos utilizados durante as dinâmicas de grupo, principalmente no projeto 3. Por vezes também recorro a um questionário com perguntas fechadas aplicado na primeira oficina do projeto 3 , nessa pequena análise quantitativa foram respondidos 17 questionários com perguntas referentes a conhecimentos, atitudes e práticas sobre sexualidade e saúde reprodutiva ${ }^{3}$.

No projeto 3 as dinâmicas giraram em torno de temas como prevenção, reprodução, cuidado, sexualidade e violência. Na medida em que o tema da sexualidade, ainda um tabú em nossa sociedade, é posto em discussão torna-se necessário um ambiente e uma relação de confiança entre os participantes das oficinas, incluindo, portanto, o chamado facilitador. Aos meninos participantes das oficinas garanti o anonimato sobre suas falas, assim como optei por não informar os nomes das instituições com as quais trabalhei. É importante acentuar que o processo de realização das oficinas foi permeado de dificuldades referentes à aproximação e aceitação pelo grupo e às próprias inseguranças e incertezas do pesquisador/educador.

Essa pesquisa careceu de entrevistas aprofundadas, dado esse fato as falas que apresentarei durante o texto são breves, pois foram retiradas do questionário de avaliação e de anotações no diário de campo. Assim como optei por não relacionar as falas a sujeitos determinados, tal estratégia se impôs a mim, pois os questionários eram anônimos. Em alguns momentos relaciono certas falas a um menino ou a uma menina o que só foi possível por anotações em campo, ou ainda porque alguns jovens assinaram ao questionário apesar da ênfase no anonimato.

Acredito que é necessário considerar as oficinas como um primeiro momento, porém não o único, de sensibilização para a tomada de atitudes mais positivas frente à epidemia da aids e para desconstrução de valores acerca da sexualidade e de questões relacionadas à hierarquia de gênero. As normas e valores repassados ao longo do processo de socialização constroem uma série de estereótipos negativos, por exemplo, em relação à homossexualidade, à atitude de passividade das meninas, dentre outros.

As oficinas aparecem, então, como um espaço de discussão que possibilita mudanças, na medida em que metodologia participativa acaba por gerar discussões nas quais outras formas de se pensar a sexualidade e as relações de gênero emergem

\footnotetext{
${ }^{3}$ Esse questionário foi aplicado para servir como um instrumento de referência para o planejamento das oficinas que seriam realizadas na instituição. 0 número de respostas a este questionário varia durante 0 texto, pois algumas alternativas permitem mais de uma resposta, como por exemplo, a pergunta com quem você conversa sobre sexo?
} 
como possibilidade. Assim também, nas oficinas podem surgir narrativas interessantes sobre as vivências desses jovens configurando um bom campo para recolher dados e para realização de pesquisas.

Nesse sentido, as oficinas configuram-se como um espaço de troca de conhecimentos de forma coletiva, podendo possibilitar um primeiro momento na busca de uma maior autonomia do sujeito em relação à epidemia da aids e à sua sexualidade. Assim como, nas oficinas de prevenção o horizonte passa a ser outro em relação a outras práticas preventivas que buscam uma mera reprodução de informações acerca de usos corretos de contraceptivos, tão comuns nas práticas de saúde.

Temos aqui uma questão que tem sido cada vez mais pertinente ao campo antropológico, dado o envolvimento cada vez maior de antropólogos que ocupam um duplo papel na realização de suas pesquisas. Refiro-me ao fato de pesquisadores que ao mesmo tempo fazem intervenções e levantam dados para a análise. Nesse sentido algumas questões éticas e metodológicas merecem atenção. Neste caso o pesquisador, ao ocupar essa dupla posição, deve atentar ainda mais para que seu texto e as informações obtidas, conforme indica o código de ética da ABA, não prejudique o grupo estudado e nem aos sujeitos envolvidos.

\section{"Meninos não Choram": a Construção Das Masculinidades}

Aúltima década foi palco de amplo debate sobre os vários aspectos que envolvem a masculinidade. Apesar da discussão sobre as relações de gênero apontar para as desigualdades que sempre privilegiaram os homens nas relações de poder, sobretudo nas sociedades ocidentais, são poucas as abordagens acadêmicas que tentam apreender as maneiras pelas quais essa masculinidade se constrói. Bem como o modo em que esse poder é interiorizado e reforçado nas relações sociais e reafirmado nas práticas cotidianas. (MEDRADO et al, 2000).

Sendo assim, pensando o gênero em seu aspecto relacional, abre-se a possibilidade de os estudos de gênero também abordarem as questões da masculinidade, já que para uma relação de mais equidade não basta rever só o papel da mulher, mas também o do homem, que passa a ter alternativas de expressão da masculinidade além daquela hegemônica. Temos agora a possibilidade de falar/agir/pensar em masculinidades no plural.

Um importante viés para entendermos a construção social das masculinidades, são as questões relacionadas à saúde reprodutiva e à sexualidade, em que se expressam 
conflitos em torno da suposta vontade feminina de fecundidade e da autonomia sexual masculina. Essa autonomia se constrói, em especial, no espaço de socialização entre os grupos de pares. Dificilmente o adolescente encontra em sua casa ou na escola espaços para colocarem questões referentes à sexualidade, suas dúvidas ou desejos (OLAVARRIA, 1999).

São muito restritos, em nossa sociedade, os espaços nos quais os adolescentes podem vivenciar a sua sexualidade, ou mesmo, os espaços nos quais possam conversar sobre ela. Normalmente temos um silêncio dentro de casa, em que a figura do pai (quando não ausente), que expressa uma importante referência em termos de identidade de gênero, ora se mantém silencioso além de não expressar sua própria sexualidade, ora educa seus filhos para um uso de poder que subordina a parceira. São poucos os pais que conversam com os rapazes, antecipando acontecimentos futuros, o mais comum é que os meninos "aprendam" por si só e com seus pares de convivência (OLAVARRIA, 1999).

0 trabalho de campo que realizei indicou que tais questões estavam muito presentes na vida dos jovens participantes da pesquisa. Como por exemplo, ao responderem a pergunta com quem você conversa sobre sexo?- contida no questionário respondido pelos garotos no projeto 3 - houve 15 respostas em que eles afirmam conversar com os amigos, 5 com a namorada(o), 03 com a mãe e 03 com o pai, 02 não conversam com ninguém e tivemos 1 resposta para professor e 1 médico e 02 para outros.

Quando questionados, durante os debates nas oficinas (projeto 3), se eles conversam sobre sexo com seus pais, os garotos normalmente diziam que não, alguns afirmaram que conversam com o pai e outros, porém em menor número, afirmaram conversar com a mãe a respeito do assunto. Sendo que o motivo, segundo eles, mais comum para não conversarem com o pai ou mãe é o sentimento de vergonha. Todos diziam que é mais fácil conversar com os amigos sobre o tema.

Em geral, tanto o pai quanto a mãe escondem sua sexualidade, assim, o ambiente da casa é visto como assexuado, ali raramente se trata da sexualidade ou se demonstra a existência de tais relações entre os adultos. Muitas vezes o pai, durante o processo de socialização do filho, o incentiva a buscar esses elementos fora, ou seja, o pai sinaliza para que o filho diferencie "mulheres que servem para casar" e estabelecer laços de "mulheres que são para satisfação de necessidades físicas".

Conseqüentemente, a casa ou o lar configuram-se, para esse jovem, como um espaço onde não acontecem relações sexuais e de prazer, bem como, acaba sendo um espaço em que o jovem não sente vontade para compartilhar suas dúvidas e suas vivências em relação a sua sexualidade. 
Assim como os professores também são tidos como assexuados, bem como nas instituições de ensino o tratamento do tema sexualidade é quase sempre limitado às questões sobre o corpo humano, sistema reprodutivo, genitais femininos e masculinos, ou seja, nada se fala sobre prazer ou desejo, ou sobre as relações sociais.

Por outro lado, temos, ao contrário da casa e da escola, o espaço da rua onde os meninos adolescentes encontram seu grupo de pares, quando se daria com mais intensidade a socialização de gênero e da sexualidade masculina hegemônica. Aí 0 garoto estaria mais aberto para dividir e incorporar desejos, fantasias e imagens corporais, bem como estaria acompanhando e interiorizando valores e atitudes dos homens que circulam em seu meio, reproduzindo comportamentos sexistas, homofóbicos e heterossexuais (OLAVARRIA, 1999).

Desse modo, como nos aponta o autor, e se confirma nas oficinas, na rua 0 adolescente constrói a imagem do homem ideal, socializando a idéia da masculinidade heterossexual superior às mulheres e aos homossexuais e aprende que o homem tem que ser ativo, corajoso, viril e forte. Este homem deve conquistar mulheres, manter sempre a capacidade de ereção e penetração, símbolos de potência, a ser vangloriada entre os pares. Há limites é claro, pois algumas intimidades não devem ser compartilhadas, principalmente aquelas vivências que são consideradas como fracasso. Nessa fase de afirmação da sexualidade, quando pesa com mais intensidade a masculinidade hegemônica, o não cumprimento dessas normas pode acarretar uma série de constrangimentos, em que os adolescentes são considerados afeminados, inferiores, doentes, anormais (OLAVARRIA, 1999).

Durante a realização das discussões em grupo no projeto 3 , foi muito comum a associação da ereção e penetração à masculinidade e foi recorrente a afirmação de que um homem nunca pode falhar. Quando perguntado aos meninos sobre o que é ser homem, era comum respostas como: é não ser mulher // não ser homossexual, enfim, apenas dois exemplos, mas posso afirmar que essas respostas reverberavam entre a maior parte dos meninos, nesse sentido era muito presente a idéia de oposição ao feminino e à homossexualidade. Outras discussões também apontaram para uma definição de ser bomem apoiado no valor trabalho e família, e ainda para a coragem de se relacionar com outros homens envolvidos em atividades ilícitas.

Entre os que responderam ao questionário, todos disseram já ter sentido "tesão" por alguém e dos que já tiveram relações sexuais, 9 entre os 17, 7 disseram sempre sentir tesão e 2 afirmaram que sentem às vezes. A maior parte dos meninos que participaram dessa oficina afirmou ainda não ter tido relações sexuais, mas durante a discussão era quase consenso que os homens sentem "tesão" com mais facilidade que 
as mulheres. E que aqueles que não sentem "tesão" ou "que falbam na bora $H$ ", esses "não são bomens".

Assim, em sua maioria, os garotos enfatizam a quase obrigatoriedade do homem sentir tesão, no sentido de que ele deve sempre manter a ereção para um bom desempenho sexual, assim como o mito em torno do tamanho do pênis apareceu constantemente nas oficinas.

0 imaginário em torno da associação, entre os meninos, do prazer sexual masculino ligado ao pênis fica evidente em uma das dinâmicas realizadas nos projetos 1 e 2. Nessa dinâmica pedíamos que os jovens modelassem em argila a região do corpo que sentem maior prazer em serem tocados. Em geral os meninos modelavam um pênis, assim como sempre comparavam entre eles o tamanho de suas "esculturas".

Já as meninas costumavam modelar diferentes partes do corpo, como pescoço, barriga, costas, seios e muitas vezes modelavam todo o corpo. É claro que entre os meninos também aparecerem modelagens de outras partes do corpo. Mas o discurso hegemônico entre os meninos era o de que o homem sente maior prazer no pênis, sendo que algumas meninas também afirmaram que preferem serem tocadas na vagina.

A fala de uma garota, em uma atividade no projeto 2, é representativa dessa idéia: senti que para os homens o que importa é ser o gostosão e para eles um pênis grande impõe respeito.

A primeira relação sexual entre os meninos geralmente é tida como um fato de afirmação, de potência e virilidade, um evento, a ser comunicado aos outros do grupo de pares como um cartão de entrada no mundo masculino heterossexual, um acontecimento que traz prestígio e status.

Na vida sexual ativa, vêem a tona os diversos ensinamentos que o jovem obteve na rua e/ou com o pai, reproduzindo os valores hegemônicos da masculinidade em que algumas mulheres assumem o papel de objeto de satisfação de necessidades naturais, enquanto outras consideradas "mulheres de respeito" merecem consideração, surgindo a possibilidade de constituição de laços amorosos. A primeira é tida como um bem a ser consumido e, para tanto, pode-se valer de uma série de recursos que vão desde falsas promessas até a violência (OLAVARRIA, 1999).

Também são atribuídos a essa "mulher objeto" os males e perigos das relações sexuais, ou seja, fica restrito a essas "outras" mulheres o risco à infecção de DST/Aids, pois são vistas como fáceis, promíscuas, diferentemente daquelas com quem pretendem estabelecer laços amorosos. Essas são "conhecidas", "confiáveis", "puras".

Tal concepção viria tanto daquele processo de socialização entre o grupo de pares, quanto pela reprodução do que os jovens viam e ouviam do pai sobre a necessidade 
de se ter cuidado com essas mulheres, pois poderiam trazer doenças ou engravidar-se para "segurar o homem". Portanto, nesses casos (e somente nesses casos), torna-se necessário o uso de preservativos. Mas e quando o preservativo não está à disposição? Prevalece a norma prescrita de que "homem que é homem não nega fogo" ou a necessidade de se tomar cuidado consigo e também com o outro?

\section{Prevenção e Saúde}

São muitas as dificuldades que permeiam um trabalho de prevenção e de pesquisa etnográfica, os problemas vão desde o levantamento de recursos financeiros (principalmente no que toca aos trabalhos de prevenção, mas que também se reflete nas investigações acadêmicas dado os escassos recursos para pesquisa em nosso país), até as inseguranças e incertezas do pesquisador/educador no complicado processo de aproximação com o grupo e com a afirmação dos laços ideais de confiança. As dificuldades para a realização de trabalhos de prevenção entre jovens exige um exercício constante de distanciamento por parte do pesquisador e/ou "facilitador" ou coordenador de oficinas de prevenção.

Discutir abertamente questões relacionadas ao sexo requer a criação de vínculos afetivos e de confiança com e entre os jovens que participam das oficinas, dado os tabus existentes em torno da sexualidade e a dificuldade de manter uma relação diferente da tradicional hierarquia presente na relação educador/educando e da dificuldade que muitos jovens, principalmente os meninos, tem em expor sentimentos e vivências, especialmente aquelas tidas como mal sucedidas.

As maiores dificuldades foram detectadas na instituição municipal técnico profissionalizante (projeto 3), em especial no inicio dos trabalhos desenvolvidos quando ficou claro uma disciplina demasiadamente punitiva, que aos poucos estava sendo questionada pela nova políica da instituição, melhorando, a meu ver, a relação entre os profissionais e os garotos. Criar vínculos afetivos e manter uma relação de liberdade respeitosa é imensamente difícil, assim como é difícil dimensionar o quanto eu pude manter essa "relação ideal", dada as diversas vezes em que a oficina não cumpriu os objetivos esperados.

No entanto, nesses "desvios" da relação ideal abriram-se outras oportunidades. Por exemplo, quando em uma oficina os jovens se mostraram avessos a qualquer tipo de atividade "organizada", resolvemos "abrir" para que realizassem outras atividades de acordo com seus interesses. Assim, nós os coordenadores, nos colocamos à disposição para quem quisesse ficar e conversar e "liberamos" os que não estavam interessados. Embora muitos tivessem saído da oficina essa negociação possibilitou 
uma maior aproximação com os garotos que ficaram e, dessa forma, acredito que demonstramos que o interesse também deveria partir deles para um bom andamento das atividades.

Esse é um problema de se realizar trabalhos - seja de pesquisa ou intervenção - em instituições que tem um cronograma muito fechado de suas atividades e que contam com poucos recursos financeiros e humanos. 0 que acaba por restringir a possibilidade de escolha dos atendidos sobre o que gostariam realmente de discutir ou de aprender. As atividades são propostas - para não dizer impostas - sem um diálogo mais consistente com o público atendido, que deveriam ter mais possibilidades de colocar suas próprias demandas.

A antropologia vem apontando para a necessidade que as pesquisas devam privilegiar aquelas questões que os interlocutores apontam como prioridade em suas vidas. Tais relações que implicam o conhecimento do "outro" nos limites de um trabalho de intervenção vêm sendo pensadas pela antropologia, sobretudo no contexto da área da saúde referente à epidemia da aids e à saúde reprodutiva. Assim, a antropologia contribui para o exercício de relativização do "outro" e de desconstruções de noções estabelecidas como naturais.

$\mathrm{Na}$ intersecção da saúde, sexualidade e gênero também são importantes as contribuições da antropologia no sentido de demonstrar a necessidade de desnaturalizar tais categorias. A importância das discussões de gênero para as questões de saúde é enfatizado por vários autores (VLLELA, 1999; GIFFIN, 1995). Em nossa sociedade, as práticas relacionadas à saúde, têm uma forte influência dos saberes da medicina ocidental moderna, dita científica, em que a regulação dos corpos se baseia na classificação do que é "normalidade" ou "doença".

Bem como, esse mesmo discurso têm influenciado no modo de pensar o indivíduo e os corpos masculino e feminino. A partir desse prisma, a mulher tem sido pensada no papel de reprodutora da espécie, enquanto para o homem fica a responsabilidade de gerador e reprodutor de bens materiais (VILLELA, 1999).

Segundo aponta Luiz Fernando D. Duarte (2003), ao tratar da relação entre pessoa/individuo e saúde/doença, em nossa cultura a vivência de "perturbações" exclusivamente "morais" é quase nula, sendo que de alguma forma a corporalidade acaba sendo relacionada na experiência vivida, mesmo de modo deslocado ou secundário.

Nesse sentido, Duarte (1988) se utiliza da categoria "perturbações físico-morais" para pensar a maneira como certas "perturbações" atuam sobre o indivíduo, sobre sua corporalidade, sobre seus sentimentos, enfim, a categoria analítica "pessoa/indivíduo" 
é utilizada para pensar a relação "saúde/doença" especialmente entre classes populares urbanas, em que parece estar a pessoa ancorada em elementos de visão de mundo mais holistas com uma preeminência do "Valor-Família" e de um modo relacional na constituição de sua identidade social.

Cláudia Fonseca (2004) ao pesquisar uma vila popular em Porto Alegre, aponta para a um sistema de valores que se constitui de acordo o espaço social ocupado na sociedade de classes. Nessa comunidade, segundo aponta a autora, o prestígio pessoal varia de acordo com idade, sexo, condição econômica e civil. No que toca aos homens jovens, o prestígio individual tem por base a bravura, a virilidade, a generosidade. A virilidade esta diretamente relacionada à conquista sexual de mulheres sem uma ligação necessária ao estabelecimento de um lar ou à procriação.

Mesmo após todas as mudanças sociais pelas quais passamos, em que a mulher passa a ocupar cada vez mais postos de trabalho, deixando de viver exclusivamente no espaço privado, e com o surgimento dos métodos de contracepção que permitem à mulher não engravidar e passar a ter a possibilidade de prazer sem necessariamente constituir qualquer laço conjugal, persiste o imaginário em torno das práticas de saúde, principalmente em relação à sexualidade e ao corpo masculino e feminino, com uma forte associação da sexualidade feminina à saúde reprodutiva e do homem ao desejo sexual quase incontrolável e da naturalizada necessidade da satisfação de prazeres (VILLELA 1999).

Desse modo, as ações voltadas às mulheres, nos serviços de saúde, partem do pressuposto de que as questões referentes à sexualidade feminina devem se apoiar no prisma da reprodução e da manutenção da harmonia conjugal. Essas práticas de ações voltadas à saúde da mulher, acabam por influenciar o que Villela (1999) chama de ações "leigas". Ou seja, práticas "não oficiais", que são aquelas efetuadas por instituições filantrópicas e movimentos de mulheres e feministas, que também centram a atenção na saúde reprodutiva e no controle da fecundidade pelas mulheres.

Esta insistência em atribuir unicamente à mulher as responsabilidades da reprodução contribui enormemente para afastar o homem de assuntos referentes à saúde sexual e reprodutiva. Em uma oficina realizada no projeto 3, em que distribuí para os garotos fichas com falas reais de dois jovens pais, e pedi para que separassem as falas que eles consideravam de mulheres daquelas que pensam ser de homens, a separação foi sempre no sentido de atribuir falas referentes ao cuidado dos filhos às mulheres e as falas sobre dificuldades para se sustentar a criança como sendo de homens. 


\section{Masculinidades e Auto-Cuidado}

Com 0 advento da epidemia de HIV/Aids, temos uma série de dificuldades para trabalhar a prevenção dentro do enfoque que até então tem sido dado à saúde reprodutiva e à sexualidade de homens e mulheres. São ainda comum as restrições morais ao comportamento sexual feminino e a complacência com as "aventuras" sexuais masculinas sem que o homem também seja responsabilizado pela proteção de ambos.

A gravidade do problema aumenta quando esse mesmo discurso associa a epidemia à grupos de risco, ou ainda, a comportamentos ditos "desviantes", responsabilizando os indivíduos pelo adoecimento. Apesar da heterossexualização da aids, e da contaminação por parte da população que não se enquadrava em nenhum dos alardeados grupos de risco manteve-se, de modo geral, a estratégia de culpabilizar 0 indivíduo e moralizar os comportamentos sexuais.

Simone Monteiro (2002) aponta para os desafios da prevenção contra o HIV em que se impõe uma estratégia que faça conexões entre estilos de vida, aspectos econômicos, sociais e simbólicos dos diferentes segmentos sociais. A autora lembra ainda que as estratégias de prevenção das primeiras décadas da epidemia (quando se formulou a idéia de grupo de risco) apoiadas na informação e na responsabilização individual foram gradualmente substituídas por abordagens que procuram problematizar as desigualdades sociais, incluindo aspectos sociais, culturais e políticos. Questões essas que são incorporadas pelo conceito de vulnerabilidade, que procura dar ênfase na articulação entre saúde pública, direitos humanos e transformação na estrutura social.

Neste contexto, investigar a construção das masculinidades torna-se um importante instrumento para possibilitar uma maior equidade entre os gêneros, um maior envolvimento dos homens para a prevenção das DSTs, HIV e aids, bem como para questões relacionadas à saúde reprodutiva e ao cuidado. A ênfase aqui deve ser dada à existência de várias maneiras de se vivenciar a masculinidade.

Em nossa cultura o homem é incentivado, desde a infância, a correr riscos como prova de coragem e/ou força física, valores esses considerados importantes e constituintes do mundo masculino, sendo sempre desmotivado quando expressa valores mais sensíveis associados aos sentimentos próprios da mulher, como aqueles relacionados ao cuidado do outro.

Nesse sentido, o homem tende a se sentir mais resistente fisicamente, o que afeta por consequiência o seu imaginário em torno do corpo e da sexualidade, interferindo nas atitudes para prevenção de doenças, entre as quais as DSTs e a aids. Outro aspecto importante é o valor da virilidade e da potência, já que muitas vezes a camisinha é tida 
como um elemento que pode atrapalhar na sensibilidade e no desempenho sexual do homem.

Alguns garotos nas oficinas do projeto 1 afirmaram como vantagens de ser homem: agente não precisa ligar muito para doenças // não precisa se previnir / I tem filho e nem sabe que tem. Tais falas apontam para o imaginário de que 0 homem é resistente às doenças, bem como ao fato de que é a mulher que deve ter cuidados com a prevenção. Nesse sentido, vejamos uma fala sobre as desvantagens de ser mulher: de pegar doenças fáceis e de ser delicada. Assim como tal imaginário interfere no uso do preservativo, sendo que dos garotos que afirmaram já ter tido relações sexuais 5 disseram sempre usar camisinhas e 4 que usam às vezes. Quando a pergunta era se eles haviam usado preservativo na sua última transa, 5 disseram que sim e 4 que não haviam usado.

Todo esse quadro contribui e aponta para compreendermos melhor o que tem colocado esses jovens em situação de vulnerabilidade para o HIV/Aids. 0 conceito de vulnerabilidade tem dado uma importante contribuição nesse sentido, merecendo com isso uma maior reflexão.

0 conceito de vulnerabilidade, segundo Medrado et al. (2000) avança significativamente em relação às estratégias até então utilizadas, na medida em que amplia a noção de risco, bem como trabalha com a inter-relação de aspectos individuais, sociais e políticos.

Os aspectos individuais são aqueles que se referem às questões de como o sujeito está refletindo as informações que tem recebido e se esta mudando suas práticas a partir daí. 0 aspecto social do conceito abrange a questão dos elementos que interferem na comunicação dessas informações e na sua qualidade, tais como os meios de comunicação que ele pode acessar, o seu grau de escolaridade, a situação econômica, o acesso à educação e à saúde, as condições de interferir nas decisões políticas, o grau de autonomia frente às barreiras culturais, principalmente no que diz respeito às relações de gênero, enfim, questões relacionadas à estrutura social. E, finalmente, o aspecto mais propriamente político, que é a necessidade de políticas públicas estarem amarradas a programas consistentes de formulação, implementação e avaliação para uma melhor otimização dos recursos disponíveis e a captação de outros de acordo com a demanda (MEDRADO et al., 2000).

Pelo que pude perceber nos trabalhos de prevenção que realizei, era forte a idéia de que o risco de infecção se restringe, ou pelo menos é bem maior entre aqueles considerados de grupos de risco. No questionário aplicado no projeto 3, 15 meninos respondeu a pergunta sobre o risco que o jovem de boje tem de pegar aids, houve 10 
respostas para um grande risco, 01 para risco médio e 01 para risco pequeno. Por outro lado, quando a pergunta refere-se ao seu próprio risco de contrair o vírus, foram 06 respostas para risco médio, 04 para risco pequeno e 02 para risco grande ${ }^{4}$.

Como se pode observar, os jovens dificilmente se sentem vulneráveis às DSTs e à Aids, sendo que durante a realização das oficinas a idéia de risco para eles está muito mais associada à violência ou a acidentes.

Além disso, para certos jovens, principalmente para as meninas, ainda há constrangimentos em levar consigo camisinhas. Como esperar então que esse jovem deva estar sempre preparado e preocupado em se proteger e incorporar práticas mais seguras para sua vida e para a vida do outro? Como superar inúmeras barreiras culturais que acabam por potencializar atitudes e práticas de riscos? Além do fato de que faltam espaços físicos para namorar, para ter relações sexuais, já que dificilmente seus pais permitem que os jovens usem suas próprias casas, por fim, faltam espaços de discussão.

Bem como devemos atentar para as dificuldades que a mulher encontra para negociar o uso de preservativos, podendo despertar desconfianças por parte do parceiro e da família. No caso da garota estar levando consigo uma camisinha, muitas vezes é tido como um indicativo de que já iniciou sua vida sexual, ferindo assim valores como o da virgindade ainda defendido (mesmo que de forma ambivalente) nos grupos populares (MONTEIRO, 2002; PAIVA, 1996).

No que se refere à questão da virgindade, no questionário respondido no projeto 3 havia as seguintes perguntas: você quer se casar virgem? Você quer se casar com alguém virgem? Houve 5 respostas afirmando que querem se casar virgem, 6 para ñ̃o e 5 para não sei. Quanto a pergunta se quer se casar com alguém virgem, foram 11 respostas para sim, nenhuma para não e 5 para não sei. A virgindade da garota normalmente é tida como um elemento positivo, como aparece em uma das falas " $a$ virgindade é ouro"e, em uma dinâmica que se pede para que descrevam uma mulher ideal, surge a imagem da mulher "que seja virgem, honesta, sincera, inteligente, leal e fiel".

Quando a menina se depara com o "problema" da gravidez, geralmente ela é culpabilizada, tanto pela idéia de que teria planejado a gravidez para "segurar 0 namorado", como pela irresponsabilidade de ter estragado seu futuro. Muitas vezes, 0 próprio parceiro duvida da paternidade e culpa a garota pela não prevenção, dado 0 imaginário de que essa é uma responsabilidade feminina.

\footnotetext{
${ }^{4}$ A idéia de grande, médio e pequeno risco é bastante homogênea, é claro que deve-se considerar contextos e situações específicas. Mas tal pergunta foi utilizada para se tentar apreender a percepção de vulnerabilidade e da percepção de risco desses meninos frente à Aids.
} 
Segundo Villa (1999), com a paternidade efetivada temos um conflito entre as expectativas geradas pelo relacionamento fixo, que traz um signo moralizante, e um outro universo representado pela autonomia sexual da vida com os pares sociais. A mulher aqui cumpre um papel de agente socializador, sendo que a constituição de uma família e a reprodução seria uma valorização positiva da masculinidade, uma confirmação de virilidade e afirmação da honra, desde que o garoto assuma o papel de homem provedor.

Outra autora que reflete essa relação é Margareth Arilha (1999) ao apontar para as associações entre a menstruação feminina, como signo da maternidade, enquanto a ejaculação masculina remeteria ao prazer sexual, sendo que a idéia de gerar filhos para os homens estaria diretamente associada à constituição da família em oposição ao prazer das aventuras sexuais e impessoais da "irresponsabilidade" da vida entre os pares.

A mesma autora indica que os significados que homens e mulheres atribuem para seus corpos e sua sexualidade parece diferir, ao passo que os rapazes tendem a pensar pouco sobre seu próprio corpo, em detrimento do que acontece com as meninas. 0 homem não se percebe enquanto "gerador da vida", idéia essa atribuída à mulher, que como prova desse poder "sangra" todos os meses. 0 imaginário em torno da menstruação acaba por incentivar as meninas a se preocuparem mais em conhecer seu corpo reprodutivo.

Algumas falas são representativas dessa idéia, em que as mulheres são tidas como as grandes portadoras das questões relativas à reprodução e à geração da vida. Vejamos algumas afirmações dos jovens com os quais trabalhei no projeto 1 acerca das vantagens e desvantagens de ser homem ou mulher. Sobre as vantagens de ser mulher: Pode dar vida a um ser humano // cuida melhor das coisas materiais e dos fithos // gerar a vida; em relação às vantagens de ser homem: bomem não menstrua // homem não senti a dor do parto.

A obrigação do homem para com o trabalho e o cuidado da mulher para com a casa e os filhos foi freqüentemente reafirmado nas oficinas no projeto 1 - tais percepções também foram freqüentes nos outros espaços em que foram realizadas as oficinas -, apesar de ser valorizada a idéia da mulher trabalhadora que "ajuda" no sustento da casa, e do homem que pode "ajudar" nas tarefas domésticas e no cuidado dos filhos. 0 "natural", como aparece em uma desvantagem de ser homem, é que "sempre é o bomem que tem que trabalhar" e a mulher é pensada como mais talentosa para cuidar da casa e dos filhos. 
0 imaginário em torno da maior afetividade feminina pôde ser percebido durante os debates realizados no decorrer das oficinas no projeto 3, como vemos na fala que remete às desvantagens de ser mulher: "que quase morre quando leva um fora", ou na vantagem de ser homem: "bomem não chora quando leva um fora", ou seja, os rapazes tendem, em geral, a classificar a sensibilidade como um atributo feminino, que por sua vez é desvalorizado pela maior parte dos meninos.

Dessa maneira vai se processando a construção de um "tipo ideal" de masculinidade, que seja heterossexual e dominante. Esse "tipo ideal" subordina as outras maneiras de viver as masculinidades, provocando, em certa medida, um distanciamento dos homens, principalmente os de classes populares, de uma relação de mais afetividade e de cuidado com o outro.

Ao tentar apreender o imaginário dos rapazes em torno do cuidado no projeto 3, me valendo de uma técnica em que se pede para falarem sobre a primeira coisa que vem a sua cabeça quando pensam na palavra cuidado e que escrevessem sobre uma cena de cuidado que tenham presenciado, os garotos enfatizam as questões em torno da violência e de acidentes. Sendo que em alguns momentos também se referiram às doenças, como vemos em algumas falas:

Eu penso, quando meu irmão era pequeno estava na barriga da minha mãe ela tomou remédio para ele não nascer mais nasceu // use camisinha // usar camisinha // tome cuidado com a aids // devemos nos prevenir de certas coisas da vida // quando não temos cuidado numa relação a mulher pode ficar grávida // ter muito cuidado para não pegar doenças // cuidado com sua vida pois ela e sua maior riqueza, cuide bem dela.

No começo desse ano eu estava esperando meu tio ele estava cortando capim de repente para um carro e eles me chamaram para entrar no carro eu não queria quase eles me pega a força eu sai correndo // assalto // cuidado com as pessoas que vc vê pois pode ser ladrões // assalto, dois meses atrás, estava passando o carro do leiteiro a, na rua da minha casa; na frente do portão e estava um cara com revolver, e outro estava sem, e outro que estava, com revolver passou para o outro que ia atirar no carro do leiteiro ele o homem que o dirigindo passou direto e o que estava com o revolver atirou na lataria // assalto: uma vez eu estava em uma pizzaria e de repente dois caras meio esquizito tiraram a arma para fora e mandou todo mundo para o chão e começou a tirar dinheiro do caixa, e depois saíram correndo e a polícia atrás // tem que tomar cuidado para deixar sua casa sozinha para que ninguém faça mal para alguém ou tentar assaltar sua casa // cuidado para não morrer irmão. 
Como podemos perceber nessas falas, é grande a associação do termo "cuidado" a crimes e à violência. Apesar de terem aparecido várias falas relacionadas às DSTs e à aids, vale lembrar que elas foram tiradas de uma oficina que discutia exatamente esses temas e, de acordo com o nosso sistema de educação escolar, é comum que muitas vezes os jovens procurem responder àquilo que o educador "quer ouvir".

\section{Gênero e Sexualidade como Construções Socioculturais}

0 material obtido me permitiu analisar como jovens de classes populares urbanas reproduzem e (re)significam valores tradicionais da cultura ocidental com relação a uma masculinidade hegemônica, qual seja: heterossexual, branca, ativa, provedora. Apesar da bibliografia em torno das masculinidades ter crescido somente nas últimas décadas, vários trabalhos apontam ainda a necessidade de pesquisas e intervenções focadas nos homens, na tentativa de desconstruir valores que dificultam práticas mais seguras em relação ao sexo e potencializam a violência nas relações de gênero. 0 viés da antropologia da saúde e dos estudos sobre gênero e sexualidade tem se mostrado um importante caminho para tratar questões relacionadas às masculinidades.

Algumas pesquisas ${ }^{5}$ nesta área mostram que preocupações em torno da ereção, da penetração e do desempenho sexual são idealizados pelos meninos, que tendem a se preocupar mais com o valorizado "sucesso sexual" do que com o risco de contrair alguma DST ou o HIV. Além disso, para os jovens participantes da pesquisa, a aids, na maior parte das vezes, ainda é pensada como a doença do "outro" e a idéia de grupo de risco permanece presente entre eles, implicando em um afastamento da possibilidade do risco, sempre distanciado, com sérias implicações para a prevenção.

Apesar de ultrapassados os conceitos de grupo de risco e de comportamento de risco e dos esforços dos movimentos de grupos contestatórios, como o dos gays, o estigma ainda pode ser percebido. Muitas vezes, durante as oficinas, surgiram falas carregadas de preconceitos, como uma delas no projeto 3 em que um garoto afirma que "aids é doença de viado", sendo que a maior parte dos garotos que participava da oficina concordou com a afirmação.

Durante toda a oficina os rapazes reproduziram tais estigmas ao provocarem uns aos outros, acusando alguns de terem aids e consequentemente serem "viados". Tais atitudes provocam risadas no grupo todo, sendo valorizadas pela maioria. Por outro lado, falas que traziam idéias mais igualitárias - a exemplo de alguns que afirmavam

5 Como exemplo dessas pesquisas temos entre outros, o dossiê da Revista Estudos Feministas sobre Masculinidade, v. 6, n. 2,1999 e Giffin e Cavalvanti (1999). 
que qualquer um hoje podia pegar aids - eram ignoradas ou depreciadas, além do que tais falas muitas vezes estão simplesmente reproduzindo um discurso politicamente correto, muito transmitido pela mídia, mais que, no entanto, é difícil dimensionar o quanto tal postura é realmente vivenciada.

Eis aqui um problema que deve ser refletido na relação entre pesquisa/ intervenção. É bom lembrar que o discurso dos jovens está situado em uma oficina de prevenção em que eles também estão falando para um sujeito situado, no caso o facilitador/pesquisador, que em alguma instância pode ser visto como uma espécie de representante do governo. Por vezes as oficinas "extravasaram" esse lugar, configurando momentos mais intensos de compartilhamento de idéias, nesse sentido o pesquisador deve estar atento para perceber esses momentos, assim como uma etnografia para além das oficinas pode trazer contribuições pertinentes para a discussão, daí a importância do referencial teórico e da prática antropológica.

Tornando-se um tema cada vez mais presente nos conflitos sociais, a sexualidade se coloca como objeto de estudo das Ciências Sociais durante os anos 80 através do diálogo entre o feminismo e a antropologia. Realizado no Brasil por autoras como Franchetto, Cavalcante e Heilborn (1981), no qual podemos observar a intrínseca relação entre gênero e sexualidade. Tal abordagem aponta para uma desconstrução de idéias essencialistas em detrimento de uma formação histórico social para os papéis de gênero e para a sexualidade.

Em relação às idéias essencialistas, tem sido discutido que a tradição do pensamento biologizante da relação entre os sexos, especialmente no que se refere a questões da área da saúde reprodutiva, sempre apontou para a naturalização de elementos tidos como inerentes à mulher/feminina e ao homem/masculino, como se a delicadeza ou o cuidado como os filhos, fosse uma característica determinante na mulher.

Ao mesmo tempo a agressividade e 0 instinto da procura pela satisfação sexual acabam sendo naturalizados para os homens. Ao contrário, o construtivismo, aponta para a relação entre determinadas características individuais a interferências de cunho social, cultural e histórico, podendo pluralizar categorias como a de masculino e feminino (HEILBORN, 1999).

Os aspectos relacionais/sociais em que os jovens elaboram suas visões de mundo, como coloca Wivian Weller (2005), atuam na construção de sua identidade. A autora aponta para a necessidade de se pensar as culturas juvenis como espaço-tempo em que experiências geracionais são construídas e descobertas, onde identidades são construídas e/ou reconstruídas. 
No que toca a antropologia, a questão etária assume importância significativa desde os anos 50, como mostra Rifiotis (1995) ao tratar da questão etária entre sociedades africanas ${ }^{6}$. Culturas diferentes podem produzir significações diferentes para as chamadas "idades da vida", relativa aos processos de socialização que remetem a um complexo sistema de aprendizado, de projeção e introjeção, de ligação e de identificação que atuam na constituição das personalidades.

Como se pode observar, são complexas as questões que envolvem a discussão da sexualidade juvenil e da prevenção do HIV/Aids, tornando-se, pois, necessário ampliar a atenção para alta vulnerabilidade desse grupo às DST/Aids, bem como para seu envolvimento com atividades ilícitas, com o abuso de drogas e com práticas violentas.

Luiz Eduardo Soares (2005) aponta que a correlação entre pobreza e violência não pode ser pensada como relações causais, diretas e mecânicas. Mas, no entanto, apesar do risco de estar contribuindo para o aumento do estigma e do preconceito, segundo o autor é um fato que esses jovens pertencentes a famílias de baixa renda, especialmente os negros, estão mais vulneráveis à violência e ao envolvimento com 0 crime.

\section{Considerações Finais}

Procurei indicar, neste artigo, as discussões e pesquisas construídas ao longo de trabalhos de prevenção que realizei na cidade de Londrina, apoiando-me na bibliografia antropológica e da saúde e tentei apreender a maneira como garotos representam e reafirmam um modo de ser homem em nossa sociedade, assim como analisar as relações sociais que levam meninos a prenderem suas lágrimas apesar de emocionados, os porquês das sanções à expressão de sentimentos sensíveis e delicados, levando os jovens das camadas populares urbanas, com os quais trabalhei, a crescerem tendo que provar a todo momento, para os outros e para si mesmos, sua virilidade, sua força, sua coragem e, principalmente, sua capacidade de conquistar mulheres.

Na nossa cultura, ocidental capitalista, os movimentos contestatórios e as ciências sociais, especificamente a antropologia, vêm tentando desconstruir noções essencialistas ao apontar para a construção histórica e cultural dos papéis exercidos por homens e mulheres.

\footnotetext{
${ }^{6}$ Rifiotis lembra que a categoria juventude e adolescência são categorias que não se constituem necessariamente em qualquer sociedade, além disso a ligação entre essas categorias e a rebelião - ou rebeldia - remete-se a uma representação do mundo adulto de nossas sociedades e são projetadas sobre os jovens. "Esta fase universal de turbulência característica do desenvolvimento pessoal, não encontra qualquer amparo antropológico, e sua razão de ser parece estar ligada às nossas projeções e contradições frente ao "adolescente", dando origem a uma fantasia dos adultos"(RIFIOTIS, 1995. p. 118).
} 
Sendo assim, procurei apontar para a necessidade de o gênero ser pensado em seus aspectos relacionais e históricos, pude articular, na medida em que me foi possível, o conceito de gênero a outras categorias como a de saúde, a de sexualidade e de classe, bem como, aliar a teoria à prática do trabalho de campo.

0 pesquisador enfrenta a difícil tarefa de por-se no lugar do "outro" e de manter 0 afastamento necessário para uma percepção objetiva. Assim, durante meu principal campo de pesquisa, a instituição municipal na qual realizei oficinas sobre sexualidade, gênero, paternidade e violência, tive que lidar com minhas inseguranças e incertezas, ao mesmo tempo em que passava pelo processo de aceitação pelos rapazes, que, de um instante para 0 outro, variavam do afeto à agressividade, da concentração à dispersão total, pois, em última instância, eu representava o "outro diferente" que ocupava 0 papel do professor, carregado de signos de disciplina, de hierarquia e de punição. Acredito que o maior desafio era romper esse imaginário e estabelecer uma relação horizontal, mais igualitária, nem sempre alcançada.

A juventude brasileira, especialmente aquela das classes populares urbanas, enfrenta uma série de dificuldades, como o acesso à educação escolar de qualidade, à bens culturais, às atividades de lazer, à um atendimento de saúde eficiente, enfim, faltam em nosso país ações e políticas públicas voltadas para essa população. 0 Estado pouco tem investido, ou tem feito de modo tímido e descontínuo. As associações, ONGs, entidades que tentam trabalhar com o adolescente e o jovem, em sua maioria, também dependem do investimento das agências estatais, seja da Educação, Cultura ou Saúde, dependência esta que acaba por limitar as atividades das instituições ou organizações não governamentais.

Nos trabalhos de prevenção dos quais participei, percebi a dificuldade de se desenvolver estratégias para a realização de projetos educacionais que tenham continuidade, pois sem ações programáticas que pensem a médio e longo prazo, que tenham a participação efetiva do jovem, e de sua comunidade, na formulação, implementação e avaliação de políticas voltadas para eles, continuará sendo difícil a realização de trabalhos que ao menos sejam consistentes.

Para tanto, é essencial a atuação do Estado por meio de políticas públicas que garantam a continuidade de projetos que tenham se mostrado eficientes na construção de conhecimentos compartilhados com os jovens. Durante a realização das oficinas pude perceber que esses jovens sentem a necessidade de espaços para que possam se expressar, discutir e se divertir. Há vontade de aprender e dividir conhecimentos, no entanto, torna-se cada vez mais difícil manter projetos sociais com qualidade e que não trazem retorno rápido. 
Uma das ferramentas de que dispomos para tentar possibilitar aos jovens maior autonomia frente ao contexto social de alta vulnerabilidade ao qual estão expostos, é a desconstrução de valores e normas estabelecidos como naturais, apontando para o modo que esses são construídos socialmente. Nesse sentido, as oficinas com metodologia participativa e a antropologia tem dado importantes contribuições.

Em relação às questões em torno da saúde, são muitos os aspectos culturais que dificultam, para os jovens, a tomada de decisões mais seguras para a prevenção de DSTs e aids. Para os meninos, é grande a dificuldade de um uso constante do preservativo, como conseqüência da necessidade imposta de responder às expectativas sociais em torno da virilidade e da potência, bem como pela associação do prazer de uma relação sexual à penetração.

Assim se pensarmos nas dificuldades que envolvem a primeira relação sexual entre os garotos, considerada como um momento de afirmação da masculinidade heterossexual, além do que, esse momento pode estar cercado de medos e inseguranças, já que a norma prescrita é a de que "um homem de verdade" nunca pode "falhar", a camisinha, por sua vez, pode acabar por ser evitada, na tentativa de diminuir as preocupações para garantir um bom desempenho. Além disso, ainda persiste o imaginário de que a camisinha diminui a sensibilidade e o prazer.

Acredito que podemos pensar as oficinas como um espaço privilegiado para que o jovem discuta assuntos referentes à sexualidade, como podemos perceber em uma das falas de um participante das oficinas de prevenção realizadas durante o projeto de extensão, ao avaliar o trabalho que realizávamos: "não nos sentimos muito presos". Bem como, outras falas que apontaram para a dificuldade de se discutir sobre sexualidade e sobre seus valores: "deixaram que nós os participantes expressassem o que pensam I/ aprendi a me abrir com as pessoas e conversar sobre coisas que não dizia para ninguém".

Outras falas são reveladoras da importância da constituição desse tipo de espaço:

Uma forma diferente de discutir prevenção // liberdade de expressão // me senti mais solto // falar sobre nós mesmos // cada um deu sua opinião // participação em grupo, gostei // na bora de falar de mulher ideal, senti que nem todos são iguais porque deram opiniões diferentes // conbecer melhor os outros // uma mistura de educação e diversão // deixaram que nós os participantes expressassem o que pensam.

As oficinas, por si só, não garantem a mudança das atitudes desses rapazes frente ao risco de infecção. Talvez esse quadro, de alta vulnerabilidade, pudesse ser alterado se as discussões em torno da sexualidade estivessem mais presentes em suas 
vidas. Para tanto, se faz necessário o envolvimento das comunidades, das famílias e de outras instituições, tais como, a escola, as igrejas e os órgãos governamentais e não governamentais. Tais instituições poderiam dar uma contribuição fundamental na promoção de debates e de políticas para a prevenção DSTs e aids.

Desse modo, os jovens poderiam efetivar sua posição de atores sociais ativos, abrindo maiores possibilidades para que sejam capazes de pressionar o Estado na criação e execução de políticas públicas contínuas e eficientes. Cada vez mais, se faz necessário, a criação de espaços e lugares para que os jovens discutam e compartilhem suas vivências. A arte, o lazer e os esportes são exemplos de atividades muito importantes para a promoção de uma vida mais justa e autônoma, que podem ajudar aos meninos e às meninas, a assumirem posturas mais positivas para sua saúde e para suas vidas.

\section{REFERÊNCIAS}

ARILHA, Margareth. Homens, saúde reprodutiva e gênero: 0 desafio da inclusão. In: GIFFIN, K; COSTA, E.S. H. (Org.). Questões de saúde reprodutiva. Rio de Janeiro: Ed. Fiocruz, 1999.

DUARTE, Luiz Fernando Dias. Indivíduo e pessoa na experiência da saúde e da doença. Ciência e Sauide Coletiva, v. 8, n.1, p. 173-183, 2003.

Da vida nervosa nas classes trabalhadoras urbanas. 2. ed. Rio de Janeiro: Jorge Zahar, 1998.

FONSECA, Cláudia. Familia, fofoca e bonra: etnografia de relações de gênero e violência em grupos populares. 2. ed. Porto Alegre: UFRGS, 2004.

FRANCHETTO, B.; CAVALCANTI, M. L. V. C.; HEILBORN, M. L. Antropologia e feminismo. In: FRANCHETTO, B.; CAVALCANTI, M. L. V. C.; HEILBORN, M. L. (Org.) Perspectivas antropológicas da mulher. Rio de Janeiro: Jorge Zahar, 1981.

GIFFIN, K. Gêneros, sexualidades e doenças sexualmente transmissíveis. In: CONGRESSO BRASILEIRO DE CIÊNCIAS SOCIAIS EM SAÚDE, 1., 1995, Curitiba.Anais... Curitiba: ABRASCO/ NESCO, 1995.

GIFFIN, Karen; CAVALVANTI, Cristina. Homens e reprodução. Revista Estudos Feministas, v. 7, n.1-2, p. 53-71, 1999.

HEILBORN, M. N. Sexualidade; o olhar das ciências sociais. In: HEILBORN, M. L. (Org.). Sexualidade; o olhar das ciências sociais. Rio de Janeiro: Jorge Zahar, 1999. 
MEDRADO, B; et al. Homens, por que? Uma leitura da masculinidade a partir de um enfoque de gênero. Perspectivas em saúde e direitos reprodutivos, n.3, p. 12-16, [2000].

MONTEIRO, S. Qual prevenção? Aids, sexualidade e gênero em uma favela carioca. Rio de Janeiro. Ed: Fiocruz, 2002.

OLAVARRIA, J. Desejo, prazer e poder: questões em torno da masculinidade heterossexual. In: BARBOSA, R. M; PARKER, R (Org.). Sexualidade pelo avesso. Direitos identidades e poder. Rio de Janeiro: IMS/UERJ, 1999.

PAIVA, V. Sexualidades adolescentes: escolaridade, gênero e sujeito sexual. In PARKER, R; BARBOSA, M. R. (Org.). Sexualidades brasileiras. Rio de Janeiro: Relume-dumará, 1996.

RIFIOTIS, T. Grupos etários e conflito de gerações: bases antropológicas para um diálogo interdisciplinar: Revista Política e Trabalho, João Pessoa, n. 11, p. 105-123, set. 1995.

SOARES, Luiz Eduardo. 0 menino invisível se arma. In: ATHAYDE, Celso; BILL, MV; SOARES, Luiz Eduardo. Cabeça de porco. Rio de Janeiro: Objetiva, 2005. p. 215-220.

WELLER, Wivian. A presença feminina nas (sub)culturas juvenis: a arte de se tornar visível. Revista de Estudos Feministas. IFCS/UFRJ; CFH/UFSC. Vol. 13. no. 1. Florianópolis, Janeiro/ abril. 2005.

VILLA, A. M. Significados da reprodução na construção da identidade masculina em setores populares urbanos. In: BARBOSA, R. M; PARKER, R (Org.). Sexualidades pelo avesso. Direitos, identidades e poder. Rio de Janeiro: IMS/ UERG, 1999.

VILLELA, W. V. Prevenção do HIV/Aids, gênero e sexualidade: um desafio para os serviços de saúde. In: BARBOSA, R. M; PARKER, R (Org.). Sexualidade pelo avesso. Direitos identidades e poder. Rio de Janeiro: IMS/UERJ, 1999. 